\title{
New Onset Diabetes after Transplantation [NODAT] Risks Factors Outcome and Possible Role of Diabetes Educators
}

\author{
Osama Gheith ${ }^{1,3^{*}}$, Nashwa Farouk ${ }^{2}$, Torki Al-Otaibi ${ }^{3}$ and Tarek Saied ${ }^{4}$ \\ ${ }^{1}$ Consultant Nephrologist, Urology and Nephrology Center, Mansoura University, Egypt \\ ${ }^{2}$ Nursing, Lecturer of Public Health Nursing, Faculty of Nursing, Mansoura University, Egypt \\ ${ }^{3}$ Consultant Nephrologist, Head of Nephrology Department, Hamad El-Essa Organ Transplant Center, Kuwait \\ ${ }^{4}$ Consultant Nephrologist, Hamad El-Essa Organ Transplant Center, Kuwait
}

*Corresponding author: Osama Ashry Ahmed Gheith, Consultant Nephrologist, Urology and Nephrology Center, Mansoura University, Egypt, Tel: 0096566641967; Email: ogheith@yahoo.com

Rec date: Oct 21, 2013, Acc date: Feb 18, 2014, Pub date: Feb 25, 2014

Copyright: (C) 2014 Gheith OA, et al. This is an open-access article distributed under the terms of the Creative Commons Attribution License, which permits unrestricted use, distribution, and reproduction in any medium, provided the original author and source are credited.

\begin{abstract}
New-onset diabetes after transplantation [NODAT] is well known complication after organ transplantation especially after solid organ transplantation, bone marrow and hematopoietic stem cells. The incidence of NODAT was observed to be different over post-transplant intervals. It has many risk factors and adverse clinical outcomes include allograft dysfunction, infections, cardiovascular morbidities, and increased mortalities among renal transplant patients. Its management should start before transplantation with special stress on risk factors, modulation of immunosuppressive agents and role of diabetes education before during and after transplantation.
\end{abstract}

Keywords: Diabetes education; Renal transplant; NODAT

\section{Introduction}

Patients with operative stress are likely to be associated with acute hyperglycemia. After one month of transplantation, most of patients recover from transplant wound especially in the absence of delayed graft function, rejection, or surgical complications. Nearly $50 \%$ of transplant patients with new onset diabetes after transplantation [NODAT] showed improvement in glucose tolerance after reduction of dosage of the immunosuppressive agents. Complete remission from NODAT is difficult to predict, however some patient with NODAT within the first year post-transplant may show partial remission $[1,2]$.

It is not known why some patients develop early-onset (within 1year after transplantation), late-onset (1-year after transplantation), or transient diabetes mellitus i.e. NODAT diagnosed within the first year post- transplantation, with recovery to normal glucose tolerance status [3].

\section{Prevalence}

New-onset diabetes after transplantation [NODAT] is a wellrecognized complication of organ transplantation especially after solid organ transplantation with different post-transplant intervals. After one year or longer of transplantation, NODAT was diagnosed in $20-50 \%$ of kidney transplants, $28-30 \%$ of heart transplants, $6-45 \%$ of lung transplants, $9-30 \%$ of liver transplants, and approximately $15 \%$ for bone marrow transplants [1,4-14] (Figure 1).

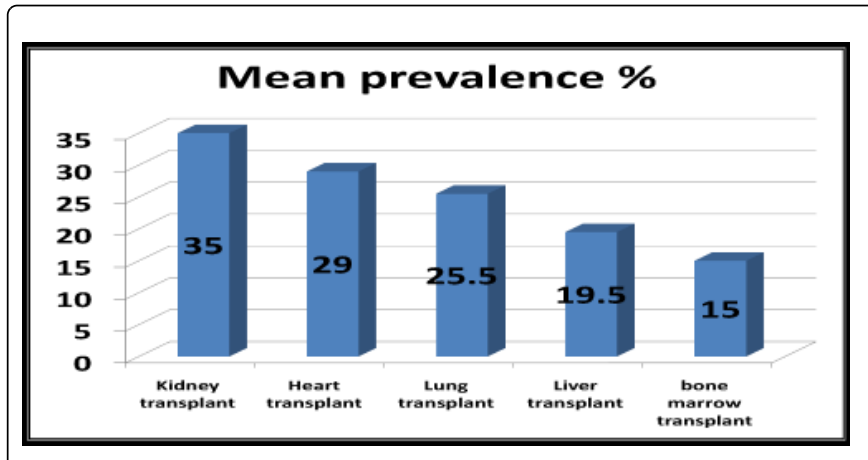

Figure 1: Showed mean prevalence percentage of NODAT among organ transplant recipients

The variation in the reported NODAT frequencies may be explained by the differences in study design, transplant populations, timing of testing, in addition to the use of non-standardized diagnostic criteria. However, since 2003 the adoption of the International Consensus Guidelines on New-Onset Diabetes after Transplantation [14] has standardized the diagnosis of NODAT.

The time of screening for diabetes can affect prevalence of NODAT. Among renal transplant recipients, the peak of NODAT developed within 12 months (up to 15\%); and falls to $6 \%$ later [15]. In contrast, its incidence increases by time in lung transplants [20.8\% at $1 \mathrm{yr}$, and $33.5 \%$ at $5 \mathrm{yr}$ post-transplant] [16]. Its cumulative incidence among cardiac transplants is nearly $30 \%$ at 5 yr [17] and up to $30 \%$ within 24 months in bone marrow transplant recipients [12]. 


\section{Complications of NODAT}

NODAT might unfavorably affect clinical outcomes of transplant recipients. This can be through renal allograft loss, precipitation of infections, cardiovascular co-morbidities, and even increased mortality among renal transplant recipients $[18,19]$. The renal hyper filtration associated with diabetes, and even high risk patients, is believed to unenthusiastically affect allograft survival. Moreover, patients with NODAT might develop micro-angiopathies faster than patients with non-transplant-related diabetes [20,21]. In liver transplant recipients with NODAT showed increased cardiovascular morbidity and mortality, more fatal infections, more neuropsychiatric complications, higher rejection rates, and poorer graft survival $[22,23]$. In lung transplants with NODAT, cytomegalovirus [CMV] infection and acute rejection episodes were observed more often [24]. Moreover, heartlung and lung showed that NODAT might be associated with higher risk for cardiac allograft vasculopathy [17].

\section{Risk Factors for NODAT}

The classical diabetes risk factors are also true in the post-transplant population [1,13,25]. Moreover, exposure to immunosuppressive agents especially steroids post-transplant patients $[1,4,15,25,26]$ (Figure 2).

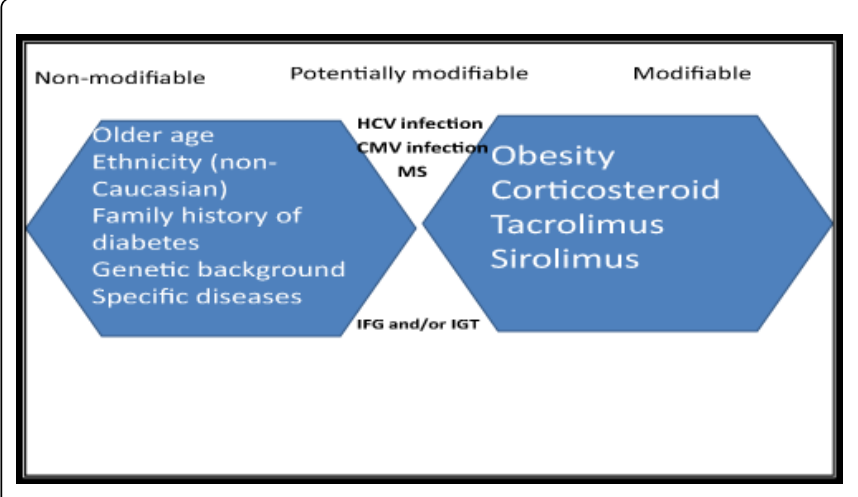

Figure 2: Showed risk factors for NODAT

Hepatitis C infection [HCV] and HLA-B13 locus had shown to be associated with higher risk of NODAT in liver or kidney transplant recipients $[27,28]$. HCV might induce diabetes through many mechanisms as pro-inflammatory cytokines, oxygen free radicals, and change of signal transduction by viral proteins, in addition to other mechanisms [29]. Other viruses like CMV infection have been associated with a 4 -fold rise in the risk of NODAT possibly due to impairment of insulin secretion [30].

\section{Role of Immunosuppressive Agents}

Posttransplant patients who do not develop NODAT are as likely to be treated with immunosuppressive agents as are patients who develop NODAT. Therefore, those who develop NODAT probably have individual vulnerability factors that are enhanced by the posttransplant environment, including exposure to immunosuppressive agents.

Glucocorticoids that are commonly consumed by transplant recipients [31] induce insulin resistance, enhance lipolysis, and increase hepatic glycogenolysis and gluconeogenesis thus increased blood sugar. Moreover, such drugs inhibit insulin secretion and stimulate glucagon release [32,33]. These effects can induce hyperglycemia in susceptible patients.

Risk factors for the development of NODAT included traditional T2DM risk factors, as older age, ethnicity (African American, Hispanic, and Native American), family history of T2DM, and obesity, in addition to other risk factors unique to post-transplantation environment such as immunosuppression, cytomegalovirus infection, hepatitis $\mathrm{C}$ seropositivity, and weight gain after transplantation. In addition, immunosuppression drugs commonly used have been implicated to be diabetogenic, including calcineurin inhibitors (tacrolimus and cyclosporine), corticosteroids, and mammalian target of rapamycin inhibitors (sirolimus and everolimus) [34], although earlier studies had raised the possibility that rapamycin inhibition of mammalian target of rapamycin may reduce the risk of diabetes [35]. The diabetogenic effects of calcineurin inhibitors are partially attributed to pancreatic A-cell apoptosis and impaired insulin secretion [36,37] additionally, there is sparse literature describing calcineurin inhibitory induced insulin resistance [15,17]. In this review, we will provide a hypothesis-driven discussion describing recent advances in our understanding of potential mechanisms involved in the diabetogenicity of calcineurin inhibitors focusing on its contribution to increased insulin resistance.

\section{Diagnosis of NODAT}

The International Consensus Guidelines on New-Onset Diabetes after Transplantation recommended that the diagnosis of NODAT be based on the American Diabetes Association criteria for the diagnosis of diabetes. Accordingly, NODAT is diagnosed by finding two fasting plasma glucose (FPG) values (measured on different days) higher than $126 \mathrm{mg} / \mathrm{dl}$; a plasma glucose level higher than $200 \mathrm{mg} / \mathrm{dl}$ at $2 \mathrm{~h}$ during a 75-g oral glucose tolerance test (OGTT) a random plasma glucose level higher than $200 \mathrm{mg} / \mathrm{dl}$ in a patient with typical diabetes clinical manifestations or A1C more than 6.5\%. If two different tests are available in an individual and the results are discordant, the test whose result is above the diagnostic cut point should be repeated, and the diagnosis is made on the basis of the confirmed test (American Diabetes Association Standards of medical care in diabetes-2011) [38]. In addition to the known pitfalls of the HbAlc test [39] blood transfusion will make results of $\mathrm{HbA} 1 \mathrm{c}$ to be unreliable.

\section{Management of NODAT}

Solid organ transplantation is now the standard of care for endstage organ failure, and primary care physicians are frequently involved in the follow-up care of transplant recipients. New-onset diabetes after transplantation [NODAT] has emerged as an increasingly important determinant of outcomes and survival in transplant recipients. Patient education and self-management are crucial for ensuring successful outcome post transplantation [40] (Figure 3). 


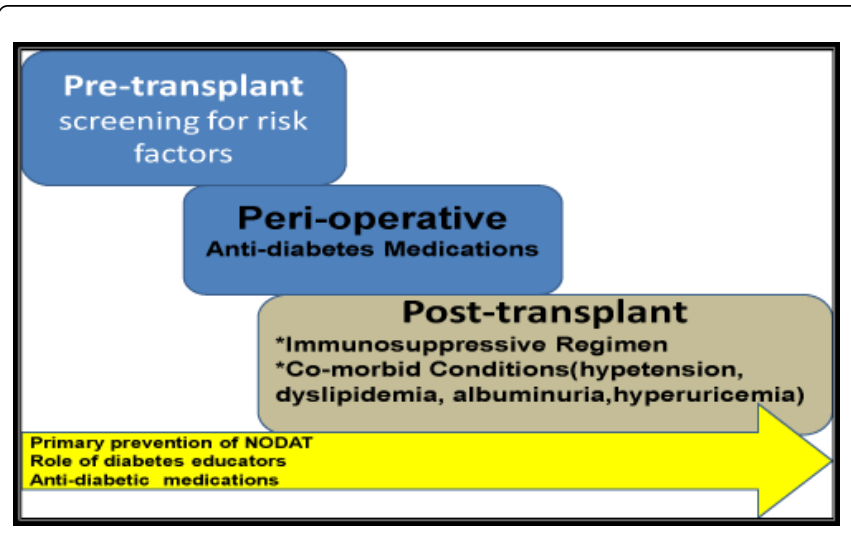

Figure 3: Showed stages of management of NODAT including all possible lines

\section{A) Pretransplant screening}

Assessment for risk factors of diabetes should be searched for once individuals are placed on the transplant waiting list. The FPG should be documented, and if it is normal, the updated International Consensus Guidelines recommend doing 75-g OGTT to detect the presence of impaired glucose tolerance (IGT) [14]. A pre transplant finding of IGT or impaired fasting glucose (IFG) is associated with higher risk for NODAT by more than 2.5 folds [41]. However, in liver transplant patients with cirrhosis or uremia (both are associated with insulin resistance and glucose intolerance), glucose tolerance may actually improve after transplantation. The ideal time to screen patients on waiting transplant list is not established yet because of relatively long duration spent by patients. The role of diabetes education came during that period for patients with risk factors of diabetes for proper weight controlled [14]. In addition; other cardiometabolic risk factors (hypertension, dyslipidemia, and smoking) should be addressed.

\section{B) Perioperative management}

Surgical stress and high-dose steroids (used as induction of immunosuppression) frequently induce early post-transplant hyperglycemia. Insulin infusion can be used to manage peri-operative stress hyperglycemia. The need of insulin therapy for controlling perioperative hyperglycemia -among kidney transplant recipients in one retrospective study- predicted a 4-fold increase in the risk of NODAT during 1st year posttransplant [42]. The glycemic targets recommended for non-critically ill patients treated with insulin (premeal blood glucose values to be less than $140 \mathrm{mg} / \mathrm{dl}(7.8 \mathrm{mmol} /$ liter) and random glucose values to be less than $180 \mathrm{mg} / \mathrm{dl}(10.0$ $\mathrm{mmol} / \mathrm{liter}$ ), may be used as a guide, given the lack of specific data for posttransplant patients [43]. Once patients begin to eat after surgery, the regimen can be changed to sc insulin (basal or basal-bolus) if hyperglycemia continues. With a decline in risk factors especially operative stress and steroid dosage, lot of patients might be weaned off insulin before their discharge. Of course, diabetes education should be started for patients who are likely to be discharged with insulin therapy especially for self-management procedures as diet, frequent blood sugar monitoring insulin adjustment, exercise, foot care, importance of regular checkup of vital organs especially the eyes.

\section{C) Post transplant monitoring}

Patients discharged without hyperglycemia should have FPG evaluation weekly during the first month, then every $3 \mathrm{rd}$ month for 1 $\mathrm{yr}$, and then annually. If IFG is detected at any time, an OGTT should be done to increase diagnostic succumb; persons identified as having IFG or IGT should receive lifestyle counseling preferably by diabetes educators [14], with special stress on diet and exercise as tolerated. Persons with NODAT, the severity of hyperglycemia is ranging from mild hyperglycemia that responds to dietary modification alone to severe elevation requiring combined therapy including insulin. All patients with NODAT should receive diabetes self-management education, including diet and exercise counseling, sick day management, and self-blood glucose monitoring. Once a diagnosis of NODAT has been confirmed in a patient who is more than 3 months posttransplant, the HbAlc can be used to monitor glycemic control [14].

\section{D) Anti-diabetes medications}

If drug therapy to control diabetes is indicated, it is wise to select agents that are suitable for the patient's underlying conditions. In transplant recipients with NODAT but with normal or adequate renal, hepatic, and cardiac function, most of the available classes of medications (including insulin sensitizers, insulin secretagogues, and incretins) can be used before considering insulin therapy. Careful attention must be considered to avoid the adverse effects of antidiabetes agents in the transplant population. Metformin should be cautiously when used in renal transplant patients with graft dysfunction because of the risk of developing lactic acidosis.

Sulfonylureas are associated with weight gain and hypoglycemia. Hypoglycemia can be severe, prolonged, and potentially fatal especially among elderly patients and those with limited hepatic function. On the other hand, glucagon-like peptide-1 (GLP-1) agonists and the dipeptidylpeptidase (DPP)-4 inhibitors are less liable to induce hypoglycemia compared with sulfonylureas. The GLP-1 agonists are linked with decreased gut motility, nausea, and occasional vomiting, which might interfere with the oral posttransplant immunosuppressive regimens. The DPP-4 inhibitors have minimal gastrointestinal adverse effects [44] and are well-tolerated by diabetic patients. However, no studies using GLP-1 agonists or DPP-4 inhibitors in the management of NODAT have been published. The thiazolidinediones -being insulin sensitizers- have less risk for inducing hypoglycemia, and used effectively in cases with NODAT [45] but adverse effect by inducing fluid retention is limiting its use.

Finally, insulin is used widely in the management of NODAT. The standard regimens (basal insulin, split-mix, and basal-bolus) are all valid in the management of NODAT. However, flexibility and originality are required to modify insulin protocols. It is usually initiated for control of severe hyperglycemia linked to an acute rejection episode that is being treated with pulse steroid. However, with decreasing the steroid dosage insulin needs will follow and close blood glucose monitoring will be essential.

\section{Immunosuppressive Regimen}

Both endocrinologists and transplant team should collaborate for proper evaluation and management of patients with NODAT to reach therapeutic decisions with possible modification of immunosuppressive agents. Certainly, in patients receiving steroidcontaining protocols, the minimal daily or alternate day steroid dose 
should be used if that can be done safely without endangering graft survival. This opinion was supported by that some studies that claim that steroid-sparing or steroid-free regimens were associated with decreased risk of NODAT [46,47], but with more controversy and more need for further evidence. Some studies involving relatively small numbers of patients have shown glycemic improvement [with occasional conversion of tacrolimus to cyclosporine $[48,49]$ which could be explained by the more potent inhibitory effect of tacrolimus on insulin secretion [35]. Thus, the emerging data suggest that the preferential use of cyclosporine (CsA) for transplant-related immunosuppression might be a rational approach to diabetes risk reduction, assuming graft protection is similar to that achieved using tacrolimus and other agents [5,48,49]. Currently, there is no agreement concerning which immunosuppressive regimen capable of preventing NODAT; however, studies aimed at CNI minimization in patients receiving potent induction therapy are enduring [50].

The gold standard of transplant management is optimal immunosuppression without untoward adverse effects through cautious use of these agents. Aiming for the lowest effective steroid dose after transplantation decreased the risk of NODAT [48,51]. Compared to CsA, tacrolimus reduces the risk of acute rejection and improves graft survival during the first year of transplantation. Lowdose tacrolimus minimizes the risk of NODAT compared to higher doses of tacrolimus. However, further studies are needed to define the best possible immunosuppressive regimen taking in consideration risks for organ rejection and NODAT [52].

\section{Co-morbid Conditions}

Attention given to diabetes co-morbid conditions should be extended to cases with NODAT as well. Thus, dyslipidemia should be managed using lifestyle modification, statin, and other possible medications. CNI are known to increase cholesterol levels, so patients may require adjustment of statin dose post-transplantation [53]. However, CNI inhibit CYP3A4; therefore, patients may receive higher exposure to statins metabolized by this enzyme [e.g. simvastatin, atorvastatin, and lovastatin]. Pravastatin and fluvastatin, which are not metabolized by CYP3A4, tends to be used preferentially in transplant patients with dyslipidemia. Fibrates may be needed for management of sirolimus and glucocorticoids associated hypertriglyceridemia and if it is severe the risk of pancreatitis is there. But the risk of rhabdomyolysis is also there especially if combined with statins, therefore fish oil can be used as an alternative.

Many organ transplant recipients are hypertensive, and posttransplant immunosuppressive agents may also increase blood pressure and the need for more anti-hypertensives. The National Kidney Foundation recommended controlling blood pressure below $130 / 80 \mathrm{~mm} \mathrm{Hg}$ in renal transplant patients [54]. Beta-blockers and calcium channel blockers appear to be well tolerated and effective [55]. Angiotensin-converting Enzyme (ACE) inhibitors and Angiotensin Receptor Blockers (ARB) are associated with reduction in glomerular filtration rate and risk of hyperkalemia and therefore should be used cautiously in renal transplant recipients. Moreover, ACE inhibitors when combined with sirolimus increased the risk of angioedema [56]. In patients with transplant renal artery stenosis (usually develops within the first $2 \mathrm{yr}$ ), ACE inhibitors and ARB may induce an acute kidney injury [55]. Despite these adverse effects, ACE inhibitors and ARB might be valuable for some patients especially in presence of proteinuria; congestive heart failure; and other appropriate indications.
The interpretation of microalbuminuria becomes complicated in diabetic kidney Transplant recipients patients. In native kidneys, albuminuria is a useful marker of diabetic nephropathy; however after kidney transplantation it is associated with glomerular injury and systemic inflammation from different causes beside diabetic nephropathy. Moreover, it is a forecaster of patient and graft survival [57].

Hyperuricemia, a feature of uremia, can be provoked after transplantation by CNI especially cyclosporine. In addition to the risk of gout, it is associated with cardiovascular disease, inflammation, insulin resistance, and decreased renal graft survival [58].

\section{Debates and Areas of Indistinctness}

\section{Primary prevention of NODAT}

The use of lifestyle intervention is possible by identifying high-risk recipients during the pretransplant period $[11,14]$. Once identified, we have to manipulate lifestyle by intervention aiming at decreasing obesity by increasing physical activity and appropriate nutrition. Lifestyle approaches customized to the transplant patients need to be developed and tested for efficacy regarding the prevention of NODAT. The approach used in the Diabetes Prevention Program [59] was effective in otherwise healthy subjects with IGT. We think that diabetes educators will have an important role in this issue. The use of medications to prevent type 2 diabetes has been well documented in the general population [60], but not yet in transplant recipients. An ideal drug for prevention of NODAT must correct or improve the gluco-regulatory defects underlying NODAT. Such a drug should have a low risk of hypoglycemia and have minimal interactions with associated post-transplant medications. In preclinical studies, exendin-4 restored the expression of insulin receptor substrate- 2 in tacrolimus-treated rodent and human islets [61]. Recent areas of investigation include clinical validation of NODAT risk score engines, validity of primary prevention of NODAT, the development of less diabetogenic immunosuppressive regimens, and potential protective effect on cardiovascular outcomes [62]. However, till now there are no data from clinical studies regarding medications for prevention of NODAT.

\section{Optimal glycemic management}

NODAT has been identified as a risk factor for graft rejection, longterm graft failure, and decreased patient survival; however the mechanisms concerning hyperglycemia to these adverse outcomes remain to be dogged. Controlled diabtes in liver transplant recipients is associated with reduction of infections [63]. Once NODAT has been diagnosed, specific anti-hyperglycemic therapy is essential to reach a tight glycemic control, which contributes to significantly reduce posttransplant mortality and morbidity [64].

As already noted, hepatic, renal, and cardiac dysfunction compel limitations to drug selection for glycemic control. Moreover, hypoglycemia can induce seizure and arrhythmia, which would be undesirable in cardiac transplant patients. Hypoglycemia also triggers adrenergic discharge and the expression of pro-inflammatory cytokines [65-73] is associated with adverse outcomes in high-risk patients. Thus, future studies are needed to determine whether recurrent hypoglycemia increases the risk of acute graft rejection and or chronic graft dysfunction. 


\section{Role of diabetes educators}

Muhlhauser and Berger [74] recommended that patients should receive evidence-based information regarding their disease to assist them in making informed decisions regarding management of their diabetes.

Higher risk of Diabetic Retinopathy [DR] is associated with longer duration of diabetes, insulin therapy, higher HbAlc level, male gender, and lower level of education, whereas higher risk of DR is also associated with lower compliance to diet control and exercise, which suggest that lower level of diabetic self-management increased the risk of DR [75].

Controversy concerning the effectiveness of diabetes education in a group setting vs. individual setting is a concern to health care providers. This issue is important to address because implementation of group education programs helps to decrease overall cost and allows more individuals to be reached at once. Rickheim et al. [76] conducted a study to assess the effectiveness of diabetes education programs when delivered in a group setting vs. an individual setting. They enrolled 170 participants from which they placed 87 in group education and 83 in individual education treatments. Education material included information on carbohydrate counting, portion control, meal spacing, self-monitoring of blood glucose, physical activity, heart-healthy eating, foot care, sick day management, monitoring for diabetes complications, self-management problem solving, and information regarding the progression of type 2 diabetes. They found significant increase in knowledge scores associated with significant decrease in $\mathrm{A} 1 \mathrm{C}$ in both treatment groups $(\mathrm{P}<0.01)$, but A1C reduction was significantly lower in the individuals receiving group education compared to the individuals receiving individual treatment $(2.5 \%$ vs. $1.7 \%, \mathrm{P}<0.01)$. Another study by Trento et al. [77] for assessment the effects of group care on the management of diabetes and the prevention of complications related to diabetes, based on their results, they conclude that diabetes education programs delivered in group settings are effective in the management of diabetes.

In the same direction, Erlich et al. [78], showed evidence that patients with diabetes who participate in a group education program have lower A1C levels, improved lipid profiles, higher quality of life scores, and improved knowledge about diabetes and problem-solving ability.

Elliott et al. [79] recommended- in an Omani study- improving knowledge transfer to people living with diabetes so that they can successfully take on more responsibility for managing their disease. They added that guidelines need to be further updated and training of providers needs to focus on improving communication skills relevant to knowledge transfer and patient education.

Improving Diabetes Self-Management and Education (DSME) has been shown effective at improving blood glucose control in multiple large scale studies $[80,81]$. Research has conclusively shown that effective health education should be provided with respect to the patients' level of education and variations in their understanding of the illness [82], since patients with diabetes who had limited literacy and lower knowledge about diabetes and self-management had poorer health outcomes [83].

A meta-analysis reviewing 84 studies regarding the effect of selfmanagement training in individuals with type 2 diabetes; Norris et al. [84] found that knowledge; frequency and accuracy of self-monitoring blood glucose, dietary habits and glycemic control were positively affected after short-term follow-up. Moreover, they added that education interventions that included patient collaboration might be more effective than didactic interventions. Thus, it seems an interactive environment in which the participants partake in the development of their diabetes management program may have additional benefits to those already seen with didactic interventions. Following ten sessions of diabetes management education program, Miller et al. [85] found that older individuals with type 2 diabetes showed significant improvements in diabetes knowledge $(P<0.0001)$, disease management skills $(P<0.01)$, and decision-making abilities $(\mathrm{P}<0.0001)$.

The learning environment should be manipulated based on the communication status of the audience. Insufficient steps to control for visual impairment could result in decreased effectiveness of diabetes management programs within this population. In the hopes of addressing this issue, Bernbaum et al. [86] examined the importance of adapting diabetes education programs for individuals with visual impairments. They concluded that an education program adapted for visual impairment provided an acceptable learning environment for participants.

Increased knowledge of diabetes management has been associated with better control of blood glucose concentrations. Harwell et al. [87] conducted a telephone survey in a rural population group and found that the participants knew their last $\mathrm{AlC}$ value, but they could not interpret the value properly. Skeie et al. [88] found that the highknowledge group, that included individuals who had diabetes for a longer time period, had a better understanding of A1C compared to the low-knowledge group. Evidence shows that as an individual's knowledge of diabetes management increases the $\mathrm{AlC}$ values decrease. Raji [89] conducted a study to investigate the effectiveness of active and passive diabetes education on $\mathrm{A} 1 \mathrm{C}$ values. It was determined that both educational interventions resulted in improved glycemic control based on A1C scores. A meta-analysis conducted by Norris et al. [90] reviewed 31 studies and they concluded that $\mathrm{A} 1 \mathrm{C}$ levels are improved by diabetes self-management education, with participant contact time being identified as the only predictor of effect (23.6 hours of contact time needed for every $1 \%$ reduction in $\mathrm{A} 1 \mathrm{C}$ levels).

In a meta-analysis done by Steinsbekk et al. [91] they concluded based on current evidence- that interventions delivered by a single educator, delivered in less than ten months, with more than 12 hours and between 6 and 10 sessions give the best results but more research is needed to confirm this. Moreover, it can be concluded that groupbased DSME in people with type 2 diabetes results in improvements in clinical, lifestyle and psychosocial outcomes.

\section{Conclusion}

Due to the importance of NODAT, diabetes education and its impact on the outcome of post-transplant morbidity and mortality become crucial point of research among organ transplant populations. Diabetes education in a group setting can be adopted for organ transplant recipients with NODAT.

\section{References}

1. Sulanc E, Lane JT, Puumala SE, Groggel GC, Wrenshall LE, et al. (2005) New-onset diabetes after kidney transplantation: an application of 2003 International Guidelines. Transplantation 80: 945-952. 
2. Arner P, Gunnarsson R, Blomdahl S, Groth CG (1983) Some characteristics of steroid diabetes: a study in renal-transplant recipients receiving high-dose corticosteroid therapy. Diabetes Care 6: 23-25.

3. Hur KY, Kim MS, Kim YS, Kang ES, Nam JH, et al. (2007) Risk factors associated with the onset and progression of posttransplantation diabetes in renal allograft recipients. Diabetes Care 30: 609-615.

4. Kasiske BL, Snyder JJ, Gilbertson D, Matas AJ (2003) Diabetes mellitus after kidney transplantation in the United States. Am J Transplant 3: 178-185.

5. Chadban S (2008) New-onset diabetes after transplantation--should it be a factor in choosing an immunosuppressant regimen for kidney transplant recipients. Nephrol Dial Transplant 23: 1816-1818.

6. Bonato V, Cataldo D, Dotta F, Carmellini M (2009) Diagnosis and approach to posttransplant diabetes. Curr Diab Rep 9: 317-323.

7. Pageaux GP, Faure S, Bouyabrine H, Bismuth M, Assenat E (2009) Longterm outcomes of liver transplantation: diabetes mellitus. Liver Transpl 15 Suppl 2: S79-82.

8. Bedanova H, Ondrasek J, Cerny J, Orban M, Spinarova L, et al. (2009) Impact of diabetes mellitus on survival rates after heart transplantation. Biomed Pap Med Fac Univ Palacky Olomouc Czech Repub 153: 283-287.

9. Ye X, Kuo HT, Sampaio MS, Jiang Y, Reddy P, et al. (2010) Risk factors for development of new-onset diabetes mellitus in adult heart transplant recipients. Transplantation 89: 1526-1532.

10. Zuckermann A, Reichenspurner H, Birsan T, Treede H, Deviatko E, et al (2003) Cyclosporine A versus tacrolimus in combination and mycophenolatemofetil and steroids as primary immune suppression after lung transplantation: one-year results of a 2-center prospective randomized trial. J Thorac Cardiovasc Surg 125: 891-900.

11. Silverborn M, Jeppsson A, Martensson G, Nilsson F (2005) New-onset cardiovascular risk factors in lung transplant recipients. J Heart Lung Transplant 24: 1536-1543.

12. Griffith ML, Jagasia M, Jagasia SM (2010) Diabetes mellitus after hematopoietic stem cell transplantation. Endocr Pract 16: 699-706.

13. Davidson J, Wilkinson A, Dantal J, Dotta F, Haller H, et al. (2003) Newonset diabetes after transplantation: 2003 International consensus guidelines. Proceedings of an international expert panel meeting. Barcelona, Spain, 19 February 2003. Transplantation 75: SS3-24.

14. Wilkinson A, Davidson J, Dotta F, Home PD, Keown P, et al. (2005) Guidelines for the treatment and management of new-onset diabetes after transplantation. Clin Transplant 19: 291-298.

15. Woodward RS, Schnitzler MA, Baty J, Lowell JA, Lopez-Rocafort L, et al (2003) Incidence and cost of new onset diabetes mellitus among U.S wait-listed and transplanted renal allograft recipients. Am J Transplant 3: 590-598.

16. Trulock EP, Christie JD, Edwards LB, Boucek MM, Aurora P, et al. (2007) Registry of the International Society for Heart and Lung Transplantation: twenty-fourth official adult lung and heart-lung transplantation report-2007. J Heart Lung Transplant 26: 782-795.

17. Marchetti P (2004) New-onset diabetes after transplantation. J Heart Lung Transplant 23: S194-201.

18. Cosio FG, Pesavento TE, Kim S, Osei K, Henry M, et al. (2002) Patient survival after renal transplantation: IV. Impact of post-transplant diabetes. Kidney Int 62: 1440-1446.

19. Hjelmesaeth J, Hartmann A, Leivestad T, Holdaas H, Sagedal S, et al (2006) The impact of early-diagnosed new-onset post-transplantation diabetes mellitus on survival and major cardiac events. Kidney Int 69: 588-595.

20. Porrini E, Delgado P, Torres A (2010) Metabolic syndrome, insulin resistance, and chronic allograft dysfunction. Kidney Int Suppl : S42-46.

21. Burroughs TE, Swindle J, Takemoto S, Lentine KL, Machnicki G, et al. (2007) Diabetic complications associated with new-onset diabetes mellitus in renal transplant recipients. Transplantation 83: 1027-1034.

22. Moon JI, Barbeito R, Faradji RN, Gaynor JJ, Tzakis AG (2006) Negative impact of new-onset diabetes mellitus on patient and graft survival after liver transplantation: Long-term follow up. Transplantation 82: 1625-1628.

23. John PR, Thuluvath PJ (2002) Outcome of patients with new-onset diabetes mellitus after liver transplantation compared with those without diabetes mellitus. Liver Transpl 8: 708-713.

24. Ollech JE, Kramer MR, Peled N, Ollech A, Amital A, et al. (2008) Posttransplant diabetes mellitus in lung transplant recipients: incidence and risk factors. Eur J Cardiothorac Surg 33: 844-848.

25. Sharif A, Baboolal K (2010) Risk factors for new-onset diabetes after kidney transplantation. Nat Rev Nephrol 6: 415-423.

26. Rigalleau V, Gin H (2005) Carbohydrate metabolism in uraemia. Curr Opin Clin Nutr Metab Care 8: 463-469.

27. Madhav D, Ram R, Dakshinamurty KV (2010) Posttransplant diabetes mellitus: analysis of risk factors, effects on biochemical parameters and graft function 5 years after renal transplantation. Transplant Proc 42: 4069-4071.

28. Saliba F, Lakehal M, Pageaux GP, Roche B, Vanlemmens C, et al. (2007) Risk factors for new-onset diabetes mellitus following liver transplantation and impact of hepatitis $\mathrm{C}$ infection : an observational multicenter study. Liver Transpl 13: 136-144.

29. Eslam M, Khattab MA, Harrison SA (2011) Insulin resistance and hepatitis C: an evolving story. Gut 60: 1139-1151.

30. Hjelmesaeth J, Sageda 1S, Hartmann A, et al Asymptomatic cytomegalovirus infection is associated with increased risk of new-onset diabetes mellitus and impaired insulin release after renal transplantation. Diabetologia 2004; 47:1550-1556.

31. Chow KM, Li PK (2008) Review article: New-onset diabetes after transplantation. Nephrology (Carlton) 13: 737-744.

32. Markell M (2004) New-onset diabetes mellitus in transplant patients: pathogenesis, complications, and management. Am J Kidney Dis 43: 953-965.

33. Crutchlow MF, Bloom RD (2007) Transplant-associated hyperglycemia: a new look at an old problem. Clin J Am Soc Nephrol 2: 343-355.

34. Yang SB, Lee HY, Young DM, Tien AC, Rowson-Baldwin A, et al. (2012) Rapamycin induces glucose intolerance in mice by reducing islet mass, insulin content, and insulin sensitivity. J Mol Med (Berl) 90: 575-585.

35. Tsang CK, Qi H, Liu LF, Zheng XF (2007) Targeting mammalian target of rapamycin (mTOR) for health and diseases. Drug Discov Today 12: 112-124

36. Ozbay LA, Smidt K, Mortensen DM, Carstens J, Jorgensen KA, et al. (2011) Cyclosporin and tacrolimus impair insulin secretion and transcriptional regulation in INS-1E A-cells. Br J Pharmacol 162: 136-146.

37. Soleimanpour SA, Crutchlow MF, Ferrari AM, Raum JC, Groff DN, et al. (2010) Calcineurin signaling regulates human islet \{beta\}-cell survival. J Biol Chem 285: 40050-40059.

38. Johnston O, Rose CL, Webster AC, Gill JS (2008) Sirolimus is associated with new-onset diabetes in kidney transplant recipients. J Am Soc Nephrol 19: 1411-1418.

39. Redmon JB, Olson LK, Armstrong MB, Greene MJ, Robertson RP (1996) Effects of tacrolimus (FK506) on human insulin gene expression, insulin mRNA levels, and insulin secretion in HIT-T15 cells. J Clin Invest 98: 2786-2793.

40. Øzbay LA, Smidt K, Mortensen DM, Carstens J, Jørgensen KA, et al. (2011) Cyclosporin and tacrolimus impair insulin secretion and transcriptional regulation in INS-1E beta-cells. Br J Pharmacol 162: 136-146

41. Heit JJ, Apelqvist AA, Gu X, Winslow MM, Neilson JR, et al. (2006) Calcineurin/NFAT signalling regulates pancreatic beta-cell growth and function. Nature 443: 345-349.

42. Rostambeigi N, Lanza IR, Dzeja PP, Deeds MC, Irving BA, et al. (2011) Unique cellular and mitochondrial defects mediate FK506-induced islet $\hat{\mathrm{I}}^{2}$-cell dysfunction. Transplantation 91: 615-623. 
43. Veroux M, Corona D, Giuffrida G, Gagliano M, Sorbello M, et al. (2008) New-onset diabetes mellitus after kidney transplantation: the role of immunosuppression. Transplant Proc 40: 1885-1887.

44. Larsen JL, Bennett RG, Burkman T, Ramirez AL, Yamamoto S, et al. (2006) Tacrolimus and sirolimus cause insulin resistance in normal sprague dawley rats. Transplantation 82: 466-470.

45. Shivaswamy V, McClure M, Passer J, Frahm C, Ochsner L, et al. (2010) Hyperglycemia induced by tacrolimus and sirolimus is reversible in normal sprague-dawley rats. Endocrine 37: 489-496.

46. Basevi V, Di Mario S, Morciano C, Nonino F, Magrini N (2011) Comment on: American Diabetes Association. Standards of medical care in diabetes--2011. Diabetes Care 2011;34(Suppl. 1):S11-S61. Diabetes Care 34: e53.

47. Dagogo-Jack S (2010) Pitfalls in the use of HbAâ,(c) as a diagnostic test: the ethnic conundrum. Nat Rev Endocrinol 6: 589-593.

48. Reynolds LR, Tannock LR (2008) Management of new-onset diabetes mellitus after transplantation. Postgrad Med 120: 60-66.

49. Iida S, Ishida H, Tokumoto T, Omoto K, Shirakawa H, et al. (2010) Newonset diabetes after transplantation in tacrolimus-treated, living kidney transplantation: long-term impact and utility of the pre-transplant OGTT. Int Urol Nephrol 42: 935-945.

50. Chakkera HA, Knowler WC, Devarapalli Y, Weil EJ, Heilman RL, et al (2010) Relationship between inpatient hyperglycemia and insulin treatment after kidney transplantation and future new onset diabetes mellitus. Clin J Am Soc Nephrol 5: 1669-1675.

51. Moghissi ES, Korytkowski MT, DiNardo M, Einhorn D, Hellman R, et al. (2009) American Association of Clinical Endocrinologists and American Diabetes Association consensus statement on inpatient glycemic control. Diabetes Care 32: 1119-1131.

52. Neumiller JJ, Wood L, Campbell RK (2010) Dipeptidyl peptidase-4 inhibitors for the treatment of type 2 diabetes mellitus. Pharmacotherapy 30: 463-484

53. Villanueva G, Baldwin D (2005) Rosiglitazone therapy of posttransplant diabetes mellitus. Transplantation 80: 1402-1405.

54. Vincenti F, Schena FP, Paraskevas S, Hauser IA, Walker RG, et al. (2008) A randomized, multicenter study of steroid avoidance, early steroid withdrawal or standard steroid therapy in kidney transplant recipients. Am J Transplant 8: 307-316.

55. Luan FL, Steffick DE, Gadegbeku C, Norman SP, Wolfe R, et al. (2009) Graft and patient survival in kidney transplant recipients selected for de novo steroid-free maintenance immunosuppression. Am J Transplant 9: $160-168$.

56. Dumortier J, Bernard S, Bouffard Y, Boillot O (2006) Conversion from tacrolimus to cyclosporine in liver transplanted patients with diabetes mellitus. Liver Transpl 12: 659-664.

57. Ghisdal L, Bouchta NB, Broeders N, Crenier L, Hoang AD, et al. (2008) Conversion from tacrolimus to cyclosporine A for new-onset diabetes after transplantation: a single-centre experience in renal transplanted patients and review of the literature. Transpl Int 21: 146-151.

58. Stevens RB, Mercer DF, Grant WJ, Freifeld AG, Lane JT, et al. (2008) Randomized trial of single-dose versus divided-dose rabbit antithymocyte globulin induction in renal transplantation: an interim report. Transplantation 85: 1391-1399.

59. Lorho R, Hardwigsen J, Dumortier J, Pageaux GP, Durand F, et al. (2011) Regression of new-onset diabetes mellitus after conversion from tacrolimus to cyclosporine in liver transplant patients: results of a pilot study. Clin Res Hepatol Gastroenterol 35: 482-488.

60. Dagogo-Jack S (2011) Medications and diabetes risk: mechanisms and approach to risk reduction. New York: Oxford University Press.

61. Marcén R (2009) Immunosuppressive drugs in kidney transplantation: impact on patient survival, and incidence of cardiovascular disease, malignancy and infection. Drugs 69: 2227-2243.

62. Kasiske BL, Zeier MG, Chapman JR, Craig JC, Ekberg H, et al. (2010) KDIGO clinical practice guideline for the care of kidney transplant recipients: a summary. Kidney Int 77: 299-311.
63. Mangray M, Vella JP (2011) Hypertension after kidney transplant. Am J Kidney Dis 57: 331-341.

64. Duerr M, Glander P, Diekmann F, Dragun D, Neumayer HH, et al. (2010) Increased incidence of angioedema with ACE inhibitors in combination with mTOR inhibitors in kidney transplant recipients. Clin J Am Soc Nephrol 5: 703-708.

65. Halimi JM, Buchler M, Al-Najjar A, Laouad I, Chatelet V, et al. (2007) Urinary albumin excretion and the risk of graft loss and death in proteinuric and non-proteinuric renal transplant recipients. Am J Transplant 7: 618-625.

66. Mazzali M (2005) Uric acid and transplantation. Semin Nephrol 25: 50-55.

67. Hernández-Molina G, Cachafeiro-Vilar A, Villa AR, Alberú J, RullGabayet M (2008) Gout in renal allograft recipients according to the pretransplant hyperuricemic status. Transplantation 86: 1543-1547.

68. Knowler WC, Barrett-Connor E, Fowler SE (2002) Diabetes Prevention Program Research Group Reduction in the incidence of type 2 diabetes with lifestyle intervention or metformin. N Engl J Med 346: 393-403.

69. Pour OR, Dagogo-Jack S (2011) Prediabetes as a therapeutic target. Clin Chem 57: 215-220.

70. Gosmanov AR, Dagogo-Jack S (2012) Predicting, managing and preventing new-onset diabetes after transplantation. Minerva Endocrinol 37: 233-246

71. Wallia A, Parikh ND, O'Shea-Mahler E, Schmidt K, DeSantis AJ, et al. (2011) Glycemic control by a glucose management service and infection rates after liver transplantation. Endocr Pract 17: 546-551.

72. Sarno G, Muscogiuri G, De Rosa P (2012) New-onset diabetes after kidney transplantation: prevalence, risk factors, and management. Transplantation 93: 1189-1195.

73. Razavi Nematollahi L, Kitabchi AE, Stentz FB, Wan JY, Larijani BA, et al. (2009) Proinflammatory cytokines in response to insulin-induced hypoglycemic stress in healthy subjects. Metabolism 58: 443-448.

74. Mühlhauser I, Berger M (2000) Evidence-based patient information in diabetes. Diabet Med 17: 823-829.

75. Li N, Yang XF, Deng Y, Gu H, Ren XT, et al. (2013) Diabetes selfmanagement and its association with diabetic retinopathy in patients with type 2 diabetes. Zhonghua Yan Ke Za Zhi 49: 500-506.

76. Rickheim PL, Weaver TW, Flader JL, Kendall DM (2002) Assessment of group versus individual diabetes education: a randomized study. Diabetes Care 25: 269-274.

77. Trento M, Passera P, Bajardi M, Tomalino M, Grassi G, et al. (2002) Lifestyle intervention by group care prevents deterioration of Type II diabetes: a 4-year randomized controlled clinical trial. Diabetologia 45: 1231-1239.

78. Erlich DR, Slawson DC, Shaughnessy A (2013) Diabetes update: population management. FP Essent 408: 25-33.

79. Elliott JA, Abdulhadi NN, Al-Maniri AA, Al-Shafaee MA, Wahlström R (2013) Diabetes self-management and education of people living with diabetes: a survey in primary health care in Muscat Oman. PLoS One 8: e57400.

80. Urbanski P, Wolf A, Herman WH (2008) Cost-effectiveness of diabetes education. J Am Diet Assoc 108: S6-11.

81. Fitzner K, Greenwood D, Payne H, Thomson J, Vukovljak L, et al. (2008) An assessment of patient education and self-management in diabetes disease management--two case studies. Popul Health Manag 11: 329-340.

82. Holmström IM, Rosenqvist U (2005) Misunderstandings about illness and treatment among patients with type 2 diabetes. J Adv Nurs 49: 146-154.

83. Rothman RL, Malone R, Bryant B, Wolfe C, Padgett P, et al. (2005) The Spoken Knowledge in Low Literacy in Diabetes scale: a diabetes knowledge scale for vulnerable patients. Diabetes Educ 31: 215-224.

84. Norris SL, Engelgau MM, Narayan KM (2001) Effectiveness of selfmanagement training in type 2 diabetes: a systematic review of randomized controlled trials. Diabetes Care 24: 561-587. 
Citation: Gheith OA, Farouk N, Al-Otaibi T, Saied T (2014) New Onset Diabetes after Transplantation [NODAT] Risks Factors Outcome and Possible Role of Diabetes Educators. J Nephrol Ther S1: S1-005. doi:10.4172/2161-0959.S1-005

Page 8 of 8

85. Miller CK, Edwards L, Kissling G, Sanville L (2002) Evaluation of a theory-based nutrition intervention for older adults with diabetes mellitus. J Am Diet Assoc 102: 1069-1081.

86. Bernbaum M, Wittry S, Stich T, Brusca S, Albert SG (2000) Effectiveness of a diabetes education program adapted for people with vision impairment. Diabetes Care 23: 1430-1432.

87. Harwell TS, Dettori N, McDowall JM, Quesenberry K, Priest L, et al (2002) Do persons with diabetes know their (A1C) number? Diabetes Educ 28: 99-105.

88. Skeie S, Thue G, Sandberg S (2001) Interpretation of hemoglobin A(1c) $(\mathrm{HbA}(1 \mathrm{c}))$ values among diabetic patients: implications for quality specifications for $\mathrm{HbA}(1 \mathrm{c})$. Clin Chem 47: 1212-1217.
89. Raji A, Gomes H, Beard JO, MacDonald P, Conlin PR (2002) A randomized trial comparing intensive and passive education in patients with diabetes mellitus. Arch Intern Med 162: 1301-1304.

90. Norris SL, Lau J, Smith SJ, Schmid CH, Engelgau MM (2002) Selfmanagement education for adults with type 2 diabetes: a meta-analysis of the effect on glycemic control. Diabetes Care 25: 1159-1171.

91. Steinsbekk A, Rygg L, Lisulo M, Rise MB, Fretheim A (2012) Group based diabetes self-management education compared to routine treatment for people with type 2 diabetes mellitus. A systematic review with meta-analysis. BMC Health Serv Res 12: 213. 